\title{
Changes in electrical activity of myometrium during intrauterine distribution of rat blastocysts and after prazosin administration
}

\author{
C. Legrand, A. Banuelos-Nevarez and J. P. Maltier \\ Université Pierre et Marie Curie, Laboratoire de Physiologie de la Reproduction, \\ C.N.R.S. URA 4, 4 place Jussieu, 75252 Paris Cédex 05, France
}

\begin{abstract}
Summary. In the early pregnant rat, electrical activity of the myometrium consisted of regular bursts of spike potential, which appeared well propagated on Day 2 of pregnancy. During Day 3, there was a gradual disappearance of propagated activity. Concomitantly, there was a 7 -fold increase $(P<0.001)$ of uterine progesterone concentrations. At this stage, mean duration of bursts was $15.2 \pm 0.9 \mathrm{sec}$ and intervals of complete quiescence between bursts were $84 \cdot 2 \pm 7 \cdot 0 \mathrm{sec}$. At 10:00 h on Day 4 , there were peaks in the uterine concentrations of oestradiol and progesterone, $+36 \%$ and $+654 \%$, respectively, compared with values on Day $2(P<0.05)$. Between 10:00 and 20:00 h on Day 4, EMG activity exhibited a rapid and transient rise: bursts were of longer duration at the utero-tubal end of the horn $(+60 \%, P<0.05)$ with an increased amplitude of spike potentials $(+67 \%$ and $+90 \%$ respectively at the tubal and cervical ends of the uterus, $P<0.05$ ). The administration of prazosin depressed EMG activity reversibly in a dose-dependent manner with maximal inhibition at about $2-3 \mathrm{~h}$ later. It is concluded that the changes observed during EMG recordings are relevant to the intrauterine distribution of blastocysts and related to changes in the steroidal environment and/or to catecholamine effects via $\alpha_{1}$-adrenoceptors.
\end{abstract}

Keywords: myometrial activity; blastocyst distribution; prazosin; rat

\section{Introduction}

In most mammalian species, data concerning the in-vivo activity of the uterine smooth muscle have been generally limited to the oestrous cycle (rat: Ishikawa \& Fuchs, 1978; cow: Ruckebush \& Bayard, 1975; sheep: Naaktgeboren et al., 1973; Prud'homme, 1976) or to the peripartum period (rat: Legrand \& Maltier, 1981, 1986; pig: Taverne et al., 1979; sheep: Prud'homme \& Bosc, 1977; Krishnamurti et al., 1982; man: Wolfs \& van Leeuwen, 1979). In the early pregnant rat (Days 2-8), EMG activity was first analysed by Talo \& Kärki (1977); the authors failed to find any change during embryo spacing but their recordings were made only once daily, between 10:00 and 11:00 h. Garcia-Villar et al. (1984) have extended these in-vivo studies in the ewe and described the motility pattern of the uterus and cervix throughout the entire course of pregnancy. They reported that EMG recordings revealed a lack of activity of the uterine muscle during the first phase of pregnancy, i.e. from Days 5 to 41 after mating. However, Pope et al. (1982a), measuring in-vitro activity of excised uterine horns of the pig, have described an increase in the frequency of muscle contractions concomitantly with embryo migration (Days 6 through 12). This observation agrees with the most likely explanation for intrauterine migration of blastocysts, i.e. that it is accomplished by myometrial activity (Böving, 1971). Indirect evidence for this hypothesis comes from the works of Pusey et al. (1980) and Rogers et al. (1983) who showed that relaxin, a potent inhibitor of myometrial activity, seriously disturbed the intrauterine distribution of rat blastocysts when 
injected intravenously before implantation. The in-vivo spontaneous activity of the uterus and its response to various regulatory agents therefore deserve more attention with regard to the migration and positioning of blastocysts since it is postulated to play an important role in establishing a successful pregnancy.

In the present experiments, we have investigated the pattern of myoelectrical activity of the early pregnant rat uterus in vivo by continuous EMG recordings from Day 2 to Day 6 of pregnancy. In our colony, transfer of blastocysts through the uterine horns begins between 11:00 and 14:00 $\mathrm{h}$ on Day 4 and is achieved late in the morning of Day 5. During this time, special attention was given to the uterine steroidal environment with regard to the pattern of EMG activity since only plasma concentrations of steroids have been previously measured (Forcelledo et al., 1981). Furthermore we have also examined the effects of prazosin administration on the myoelectrical activity of the early pregnant uterus; it has been previously demonstrated that this specific $\alpha_{1}$-adrenergic antagonist seriously disturbed the distribution and spacing of blastocysts in the rat uterus (Legrand et al., 1987).

The aim of the present study was to elucidate the temporal relationships between EMG activity of the uterus, its steroidal environment and responsiveness to $\alpha_{1}$-noradrenergic transmission and intrauterine blastocysts distribution.

\section{Materials and Methods}

\section{Animals}

Virgin female Sprague-Dawley rats weighing between 250 and $300 \mathrm{~g}$ were housed under controlled temperature $\left(22^{\circ} \mathrm{C}\right)$ and photoperiod $(10 \mathrm{~h}$ light and $14 \mathrm{~h}$ darkness with the lights on from 08:00 to 18:00 h). Food and water were available ad libitum. The females were caged with males overnight and successful mating was determined by the presence of spermatozoa in the vaginal smear (Day 1 of pregnancy or post coitum).

\section{EMG activity of the uterus}

Pairs of electrodes constructed from insulated wires (nickel-chrome blending 80/20) with a cross-section of $80 \mu \mathrm{m}$ were used to detect activity in the myometrium. At 09:00 h on Day 2 of pregnancy, two pairs of electrodes were sewn into the myometrium, one at $1 \mathrm{~cm}$ from the utero-tubal junction and the second at $1 \mathrm{~cm}$ from the cervical end of the same uterine horn. The distal tips of the wires were scratched free of insulation for a distance of $2 \mathrm{~mm}$ and inserted, 2-3 mm apart, between the antimesometrial and mesometrial poles of the uterus. The distance between pairs of electrodes was $2-3 \mathrm{~cm}$. Wires from the electrodes were exteriorized at the back of the neck and the free ends were ensheathed in a metallic cable. After surgery the animals were housed individually; the length of the electrodes and the cable allowed them to move freely in their cage. They received food and water ad libitum. Signals were amplified using an ink-writer polygraph (E.C.E.M.) with a time constant of $0.03 \mathrm{sec}$ and with a pass filtering set at $3 \mathrm{~Hz}$. Two groups of experimental animals were used.

Normal pregnant rats. Some females $(\mathrm{N}=12)$ were left untreated after surgical procedures to detect normal activity of the myometrium. All recordings were analysed by measuring frequency and duration of electrical burst activity and amplitude of the spikes, at the ovarian and cervical ends of the uterine horn. EMG was recorded continuously after surgery. EMG was quantitated over a period of $S \mathrm{~h}$ during the afternoon of Day 2 and during the entire period from 14:00 h on Day 3 to 18:00 h on Day 5. At 18:00 h on Day 5 or 10:00 h on Day 6, animals were lightly anaesthetized with ether and $1 \mathrm{ml}$ of a $1 \%$ Evans' blue solution in saline $(9 \mathrm{~g} \mathrm{NaCl} / \mathrm{l})$ was injected into the saphenous vein. After $30 \mathrm{~min}$, the uterine horns were exposed to localize blue band reactions at blastocyst sites (Psychoyos, 1961, 1971). Then, they were removed and fixed in Carnoy's reagent before being processed for routine light microscope histology.

Prazosin responsiveness. Prazosin is a quinazoline (De Marinis et al., 1987) which is considered to act as a powerful post-synaptic $\alpha_{1}$-adrenergic blocking agent (Ruffolo, 1984). Its effect on the development of myometrial activity was determined between 13:00 h and 22:00 h on Day 4 from both pairs of electrodes. In a preliminary study (Legrand $e t$ al., 1987) there was an indication that this drug, when injected at approximately the same time, reduced the recovery rate of blastocysts in the cervical end of the uterine horns. Graded doses of prazosin (prazosin-HCl: Pfizer, Brussels, Belgium; $0.75,1.5$ and $3 \mathrm{mg} / \mathrm{kg})$ in $0.5 \mathrm{ml}$ saline $(0.9 \% \mathrm{NaCl})$ plus ethanol $(10 \%)$ were administered to establish doseresponse curves of myometrial activity. For this study, 3 groups of 6 rats were used, each rat receiving successively the 
three doses of prazosin plus the vehicle. Vehicle was given $1 \mathrm{~h}$ before the drug. Administration of prazosin or vehicle was made without disturbing the animal by a catheter which was inserted intraperitoneally under general anaesthesia during surgery for EMG. It was then led subcutaneously to the back of the neck of the animal and exteriorized there with the electrodes. EMG recordings were analysed over a period of $15 \mathrm{~min}$ to $8 \mathrm{~h}$ after treatments.

\section{Radioimmunoassays for progesterone and oestradiol}

Control pregnant rats $(\mathrm{N}=50)$ were killed by cervical dislocation between $10: 00 \mathrm{~h}$ on Day I and 10:00 h on Day 8 of pregnancy for radioimmunological assays of uterine progesterone and oestradiol. In another group of 21 pregnant rats, pairs of electrodes were inserted into the myometrium in the same manner as described above. These rats were killed at $20: 00 \mathrm{~h}$ on Day 3, 10:00 h on Day 5 or 10:00 h on Day 6 of pregnancy to test the effects of the surgical procedure on the concentrations of progesterone and oestradiol in uterine horns bearing the electrodes.

For RIA procedures, the uteri were rapidly isolated and frozen in liquid nitrogen. They were homogenized in $1 \mathrm{ml}$ ice-cold $0 \cdot 1 \mathrm{M}$ phosphate buffer ( $\mathrm{pH} 7 \cdot 0$ ) with an Ultra Turrax. The homogenates were then transferred to extraction tubes. Tritiated steroids (about 1000 c.p.m. steroid in $\mathrm{I} \mathrm{ml}$ phosphate buffer) were added to each sample for estimation of procedural losses. Extraction was performed by vigorous mixing of sample and $2 \times 4$ ml anhydrous ether with a Vortex mixer for $30 \mathrm{sec}$. After the aqueous layer had been frozen in an ethanol-solid $\mathrm{CO}_{2}$ mixture, the ether extract was poured into a glass tube and evaporated to dryness under filtered air. The dry residue was dissolved in $2 \times 100 \mu l$ benzene-ethanol $(90: 10, \mathrm{v} / \mathrm{v})$. Progesterone and oestradiol-17 3 were separated by Sephadex LH-20 column chromatography. Elution was carried out using benzene-ethanol $(90: 10, \mathrm{v} / \mathrm{v})$. Specific antisera raised against bovine serum albumin (BSA) conjugates (kindly donated by Dr M. Mouren, Roussel-Uclaf, Romainville, France) were used for the assays. The cross-reactivity of antiprogesterone-3-(CMO)-BSA was $40 \%$ for $5 \alpha$-pregnanedione, $4 \%$ for deoxycorticosterone, $3.5 \%$ for $17 \alpha$-hydroxyprogesterone and $<3 \%$ for all other steroids. The cross-reactivity of antioestradiol$7-(\mathrm{CMO})-\mathrm{BSA}$ was $3.8 \%$ for oestriol, $2.3 \%$ for oestrone and $<0.5 \%$ for all other steroids. The standard curves ranged from 0 to $600 \mathrm{pg}$ per assay tube for progesterone and from 0 to $300 \mathrm{pg}$ per assay tube for oestradiol-17ß.

About 2500 c.p.m. of tritiated progesterone $\left(1 \alpha, 2 \alpha(n)-\left[{ }^{3} \mathrm{H}\right]\right.$ progesterone, sp. act. $55 \mathrm{Ci} / \mathrm{mmol}$ : Radiochemical Centre, Amersham, UK) and about 4000 c.p.m. of tritiated oestradiol $\left(6,7-\left[{ }^{3} \mathrm{H}\right]\right.$ oestradiol, sp. act. $60 \mathrm{Ci} / \mathrm{mmol}$ : Radiochemical Centre, Amersham, UK) and $200 \mu \mathrm{l}$ of antiserum diluted at 1:5000 for progesterone and 1:50 000 for oestradiol-17 $\beta$ were successively added to each tube. Bound steroid was separated from free steroid by a Dextrancoated charcoal step. The supernatant of each sample was then transferred to a scintillation vial and counted in a Liquifluor-toluene $(0 \cdot 4: 10, \mathrm{v} / \mathrm{v})$ scintillation mixture at $70 \%$ efficiency in a LKB-Wallac Spectrometer (1214 Rackbeta). The intra-assay and inter-assay coefficients of variation were respectively $3 \cdot 2 \%$ and $14.9 \%$ for progesterone and $3.6 \%$ and $13.9 \%$ for oestradiol. The sensitivity of the assay was $37 \mathrm{pg} / \mathrm{ml}$ for progesterone and $6.5 \mathrm{pg} / \mathrm{ml} \mathrm{for}$ oestradiol.

\section{Data analysis}

All data presented are given as mean \pm s.e.m. For RIAs, differences amongst groups were tested by paired comparisons (Student's $t$ test). For testing differences in EMG recordings, between stages of pregnancy, or treatments, or between tubal and cervical ends of the uterine horn, the results were analysed by one-way analysis of variance (ANOVA) followed by Duncan's multiple range test. A difference was considered statistically significant when the double tail $P$ value was $<0.05$.

\section{Results}

\section{Effects of surgical preparation for myometrial activity recording}

Amongst the 12 rats that had been prepared for EMG activity recordings and then autopsied after $18: 00 \mathrm{~h}$ on Day 5, 3 rats were not pregnant, 2 were unilaterally pregnant and 7 bilaterally pregnant. Only this last group of rats was used for electrical activity measurements.

The mean number of blastocysts counted (by means of the Evans' blue reaction) in the 7 gravid uterine horns bearing electrodes was $3.7 \pm 0.4$, i.e. $56 \%(P<0.01)$ of the total blue sites visualized in the contralateral uterine horn $(6.6 \pm 0.8)$ without electrodes. However, histological sections of the uterine horn submitted to the surgical procedure for EMG recordings showed no deleterious effects on implantation sites since, on Day 5 or 6 , the morphology of uterine tissues surrounding blastocysts and the extent of the primary decidual reaction were unchanged (Figs 1 and 2 ). There was some proliferation of uterine connective tissues close to the electrode insertions between the longitudinal and circular layers of the myometrium (Fig. 1). 

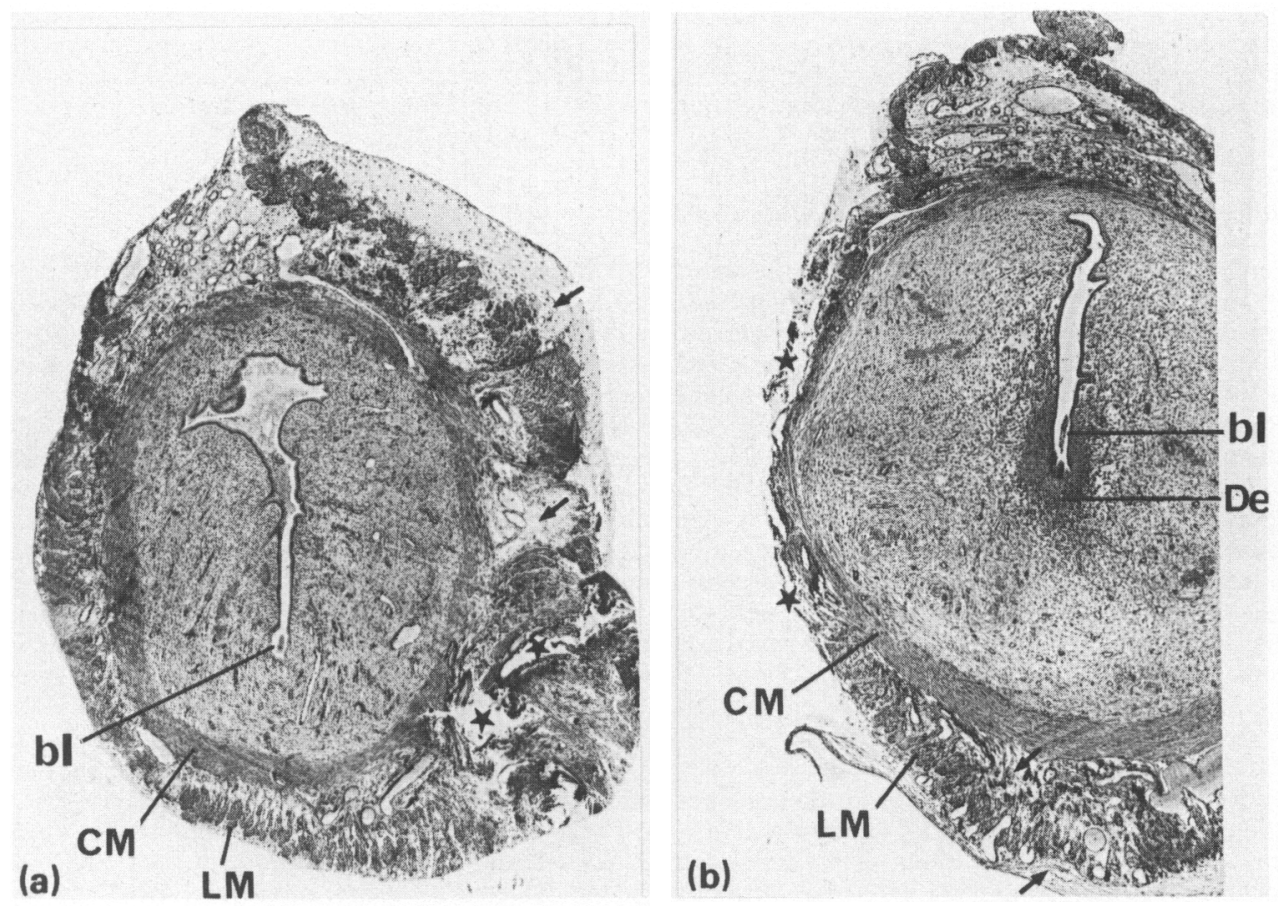

Fig. 1. Transverse sections of rat uterine horn (a) at 18:00 h on Day 5 and (b) at 10:00 h on Day 6. Two pairs of electrodes were sewn into the myometrium at $09: 00 \mathrm{~h}$ on Day 2. Arrows show intensive proliferation of uterine connective tissues close by one pair of electrodes (asterisks) inserted between the longitudinal layer (LM) and circular layer (CM) of the myometrium. One blastocyst (bl) can be seen at the implantation site. In (b) note the normal extent of the primary decidual reaction $(\mathrm{De}) . \times 80$.

\section{Spontaneous activity of the myometrium}

In early pregnancy, electrical activity of the myometrium consisted of regular bursts of spike potentials, the amplitude of which was variable, as it was for the duration and frequency of these bursts. This variability depended on the stage of pregnancy and on the position of the electrodes at the tubal or cervical end of the uterine horn (Fig. 3a). Between 14:00 and 19:00 h on Day 2 post coitum, no difference was found between electrical activities recorded at the two extremities: mean duration of bursts was $15.2 \pm 0.9 \mathrm{sec}$, intervals of complete quiescence between bursts were $84 \cdot 2 \pm 7 \mathrm{sec}$ and frequency of the bursts was $40-45$ per hour. At this stage of pregnancy, bursts were considered to be propagated from the utero-tubal to the cervical end of the uterine horn; indeed a temporal relationship was evident between activities at the two recording sites where the number of coincident bursts were similar (Fig. 3a). Speed of propagation between both pairs of electrodes, placed $2-3 \mathrm{~cm}$ apart along the uterine horn was estimated to be $5-7 \mathrm{sec}$ (Fig. 3a). During Day 3 of pregnancy, there was a gradual disappearance of propagated activity. On Days 4 and 5 , the relationship between individual bursts recorded at both pairs of electrodes was disorganized (Fig. 3a).

During Day 4 of pregnancy, EMG activity showed a rapid and transient elevation. Between 10:00 and 20:00 $\mathrm{h}$ the mean amplitude of spike potentials increased from $64 \pm 3 \mu \mathrm{V}$ to $107 \pm 6 \mu \mathrm{V}$ $\left(\mathrm{F}^{1}{ }_{11}=16.44, P<0.005\right)$ at the utero-tubal end and from $50 \pm 5 \mu \mathrm{V}$ to $95 \pm 7 \mu \mathrm{V}\left(\mathrm{F}^{1}{ }_{10}=21 \cdot 87\right.$, $P<0.05$ ) at the cervical end of the same horn (Fig. 4a). Concomitantly, bursts at the utero-tubal end were of longer duration: $9 \cdot 9 \pm 2.5 \mathrm{sec}$ at $10: 00 \mathrm{~h} v s$ 16.5 $\pm 1 \cdot 2 \mathrm{sec}$ at 18:00 $\mathrm{h}$ on Day 4 

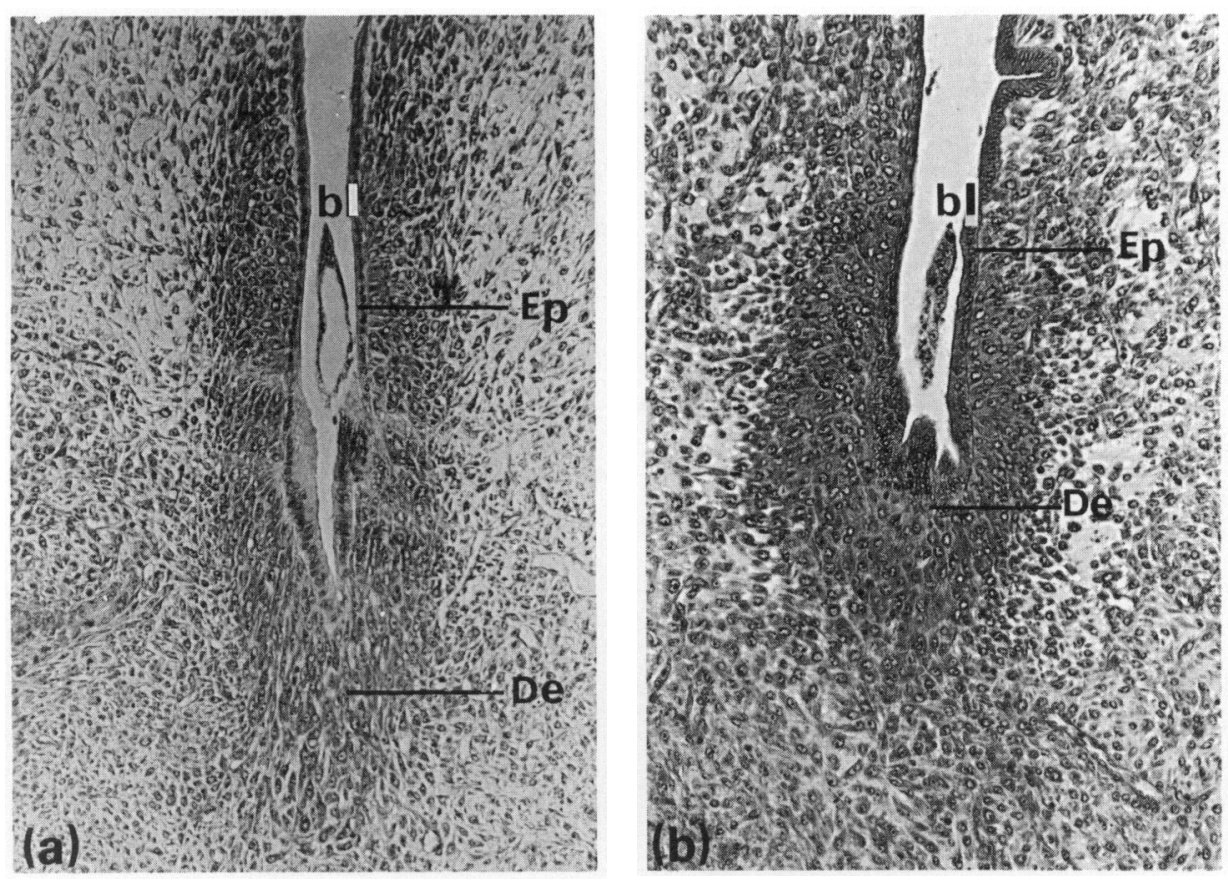

Fig. 2. Transverse sections of an implantation chamber at 10:00 h on Day 6 (a) in the intact uterine horn or (b) after insertion of electrodes into the myometrium. The blastocyst (bl) is in close contact with uterine epithelial cells (Ep) and the primary decidual reaction (De) is well developed. $\times 120$.

$\left(\mathrm{F}_{11}^{1}=5 \cdot 17, P<0.05\right)$ (Fig. $4 \mathrm{~b}$ ); there was no significant change at the cervical end of the horn $(13.3 \pm 2.5 \mathrm{sec}$ at $10: 00 \mathrm{~h}$ os $15.7 \pm 1.9 \mathrm{sec}$ at $18: 00 \mathrm{~h})$ (Fig. $4 \mathrm{~b}$ ).

Later in the evening, the interval of quiescence between bursts was shortened to $20.8 \pm 1.3 \mathrm{sec}$ at the utero-tubal extremity of the uterine horn but not at the cervical end where it remained unchanged. Consequently the mean frequency of electrical bursts appeared greatest only at the utero-tubal end where it was increased from $45 \pm 8$ at 10:00 h on Day 4 to $107 \pm 10$ at 01:00 h on Day $5\left(\mathrm{~F}_{6}{ }_{6}=16 \cdot 15, P<0 \cdot 01\right)$ (Fig. $\left.4 \mathrm{c}\right)$.

During the next $14-16 \mathrm{~h}$, EMG activity decreased gradually to reach values similar to those found before 10:00 h on Day 4 .

\section{Prazosin responses}

The effects of prazosin on myometrial activity were analysed from 13:00 to 21:00 h on Day 4 and the dose-response curves were as illustrated in Fig. 5. By taking into account the fact that prazosin was bound by $93 \%$ to plasma proteins (see Hobbs \& Towmey, 1979), these curves provide an estimate of the $\mathrm{ED}_{50}$ (dose of drug that produces one-half of the maximal response) of about $40 \mathrm{~nm}$ (data not shown). The amplitudes of the changes induced by the drug were not significantly different at the two extremities of the uterine horn and so values were pooled. Curves clearly showed that there was a marked inhibition on the frequency of bursts of EMG activity and on the amplitude of spike potentials at doses of $0.75,1.5$ and $3 \mathrm{mg}$ prazosin/ $\mathrm{kg}$. The time of onset of the prazosin effect was about 10 min with maximal inhibition at about $2 \mathrm{~h}$ later. At this time, the mean amplitude of the spikes was decreased, compared with the effect of vehicle, by $31 \%\left(\mathrm{~F}_{8}^{1}=70 \cdot 0\right.$, $P<0.0001)$ after $1.5 \mathrm{mg}$ prazosin $/ \mathrm{kg}$ and by $65 \%\left(\mathrm{~F}_{6}{ }_{6}=342.2, P<0.0001\right)$ after $3 \mathrm{mg}$ prazosin $/$ $\mathrm{kg}$; moreover there was a statistically significant difference between the two doses of the drug 


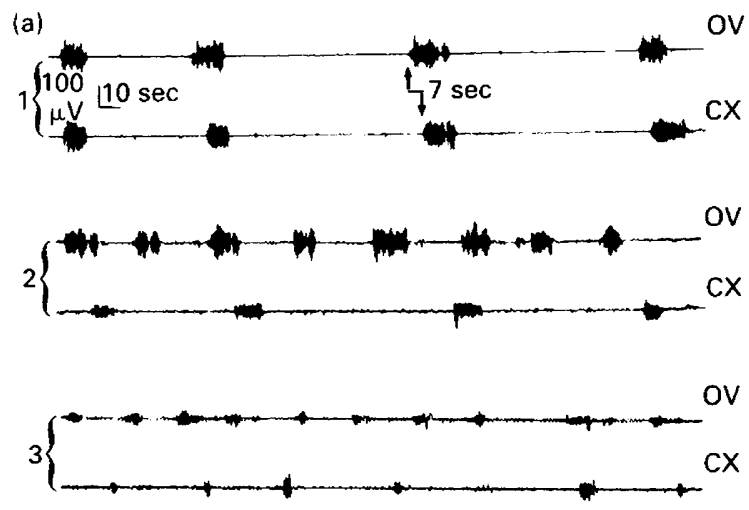

(b)

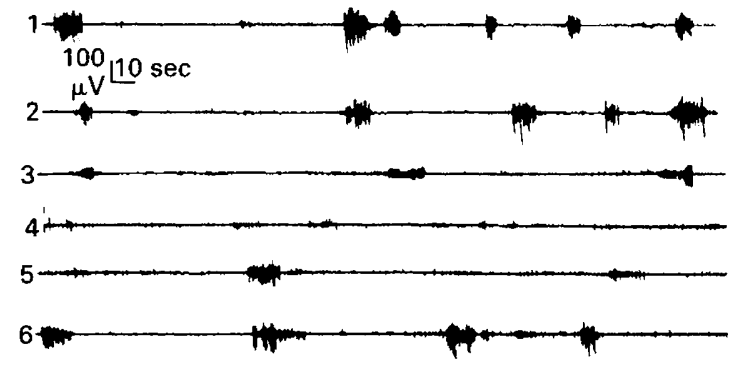

Fig. 3. Electrical activity recorded (a) from the ovarian end (ov) and cervical end (cx) of one uterine horn of the same rat at (1) 15:00 h on Day 2, (2) 16:00 h on Day 4 and (3) 02:00 h on Day 5, and (b) from the utero-cervical myometrium of the same rat at (1) 13:00 h on Day 4, (2) $+1 \mathrm{~h}$ after vehicle for prazosin, and (3) $+15 \mathrm{~min},(4)+1 \mathrm{~h},(5)+3 \mathrm{~h}$ and $(6)+6 \mathrm{~h}$ after administration of $1 \mathrm{mg}$ prazosin.

$\left(\mathrm{F}_{6}^{1}=40 \cdot 7, P<0.005\right)$. Simultaneously, frequency was diminished by $34 \%\left(\mathrm{~F}_{8}^{1}=12.9\right.$, $P<0.01)$ with $1.5 \mathrm{mg}$ prazosin $/ \mathrm{kg}$ and by $49 \%\left(\mathrm{~F}_{10}^{1}=252.9, P<0.0001\right)$ with $3 \mathrm{mg}$ prazosin $/ \mathrm{kg}$.

The effects of prazosin on the duration of the bursts were more complex. Curves were biphasic and revealed a transient elevation only during the initial $30 \mathrm{~min}$ after prazosin administration and then, burst duration was reduced to the same level as in vehicle-treated rats with $1.5 \mathrm{mg}$ prazosin $/ \mathrm{kg}$ and by $36 \%\left(\mathrm{~F}_{6}^{1}=486, P<0.0001\right)$ with $3 \mathrm{mg}$ prazosin $/ \mathrm{kg}$. The inhibitory response time was always dose-dependent, with the highest dose of prazosin producing a longer inhibition than the lower one (Figs 5a, b, c).

The inhibitory effect of prazosin appeared progressively reversible after a delay of $4-8 \mathrm{~h}$. Administration of vehicle caused no significant change in myometrial electrical activity (Figs 5a, b, c).

The electrical activity of the utero-cervical myometrium before and after a single injection of $1 \mathrm{mg}$ prazosin per rat at 15:00 h on Day 4 is illustrated in Figs 3(b) and 6.

\section{Uterine steroid concentrations}

The changes of uterine concentrations of progesterone and oestradiol before and during implantation are represented in Fig. 7. In normal (untreated) pregnant rats, the more pronounced change for progesterone was a rapid 7-fold increase from 10:00 h on Day 2 to 10:00 h on Day 3 (respectively $7.0 \pm 1.0 \mathrm{ng} / \mathrm{g}$ and $52.8 \pm 3.1 \mathrm{ng} / \mathrm{g}, P<0.001$ ) which continued from Day 3 to Day 5 $(75.0 \pm 9.0 \mathrm{ng} / \mathrm{g})$. Thereafter the uterine concentrations of progesterones decreased lightly and then 


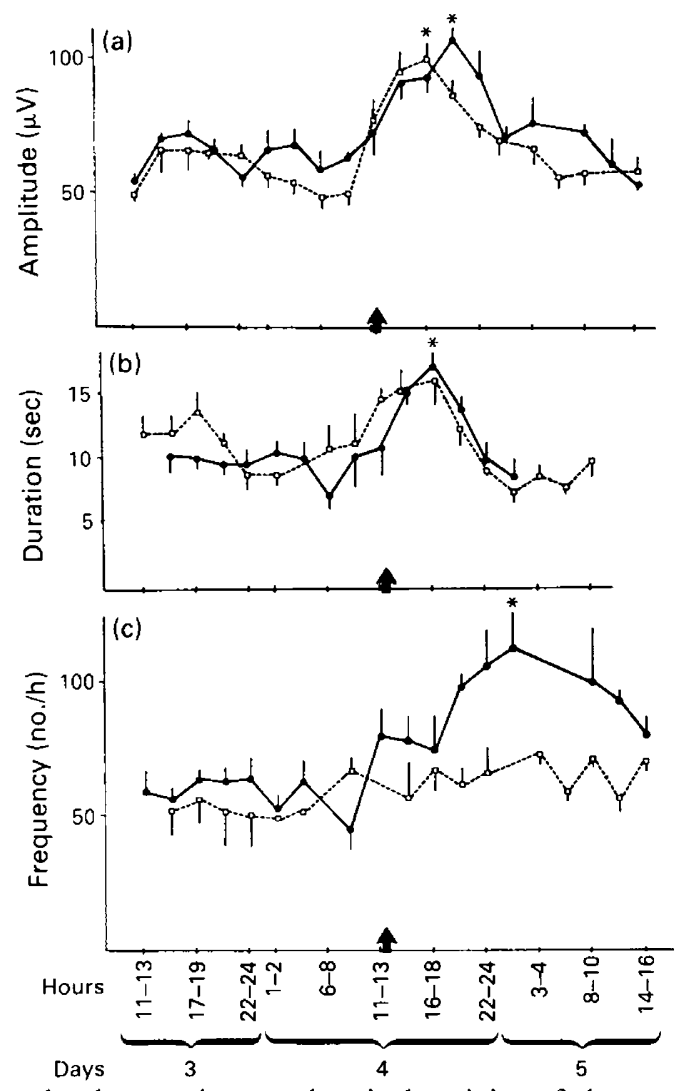

Fig. 4. Daily and hourly changes in myoelectrical activity of the ovarian end (- a) and cervical end $\left(O_{--}\right)_{\text {) }}$ of the uterine horns: (a) amplitude of spike potentials, (b) duration of the bursts and (c) frequency of bursts. Arrow indicates the time when blastocysts enter the uterus. ${ }^{*} P<0.05$ vs 10:00 h on Day 4, N (no. of rats) $=7$ from Day 2 to $21: 00 \mathrm{~h}$ on Day 4; $\mathrm{N}=4$ from 22:00 h on Day 4 to 03:00 h on Day 5; $\mathrm{N}=3$ from 04:00 h to 14:00 h on Day 5.

remained stable between Day 6 and Day 8 reaching a plateau around $55 \mathrm{ng} / \mathrm{g}$. Uterine concentrations of oestradiol increased progressively after Day 1, exhibiting a peak value at 10:00 h on Day $4(279.0 \pm 35.9 \mathrm{pg} / \mathrm{g}$ vs $103.5 \pm 28.1 \mathrm{pg} / \mathrm{g}$ on Day $1, P<0.001)$; they then decreased sharply from day to day to reach basal values on Day $8(11.0 \pm 9.0 \mathrm{pg} / \mathrm{g}, P<0.001)$. Uterine concentrations of progesterone and oestradiol were not significantly changed after the surgical procedure for EMG activity (Fig. 7).

\section{Discussion}

The present electrophysiological observations in vivo of the uterus of the intact rat provide detailed information on the pattern of activity of the myometrium associated with intrauterine distribution and positioning of blastocysts. The electrical activity of the myometrium undergoes transient characteristic elevation from Day 4 to Day 5, i.e. at a time when blastocysts are moving throughout the uterine horns. In our colony of Sprague-Dawley rats, transfer of fertilized ova to the uterine horns begins between 11:00 and 14:00 h on Day 4 and is achieved by the morning of Day 5. At 10: $00 \mathrm{~h}$ on Day 5, blastocysts are distributed throughout the uterine horns. They shed the zona pellucida at about 15:00-16:00 $\mathrm{h}$ and their attachment to the uterine epithelium at implantation sites is achieved by $18: 00 \mathrm{~h}$ on Day 5 . This timing of events is in good agreement with previous data of 

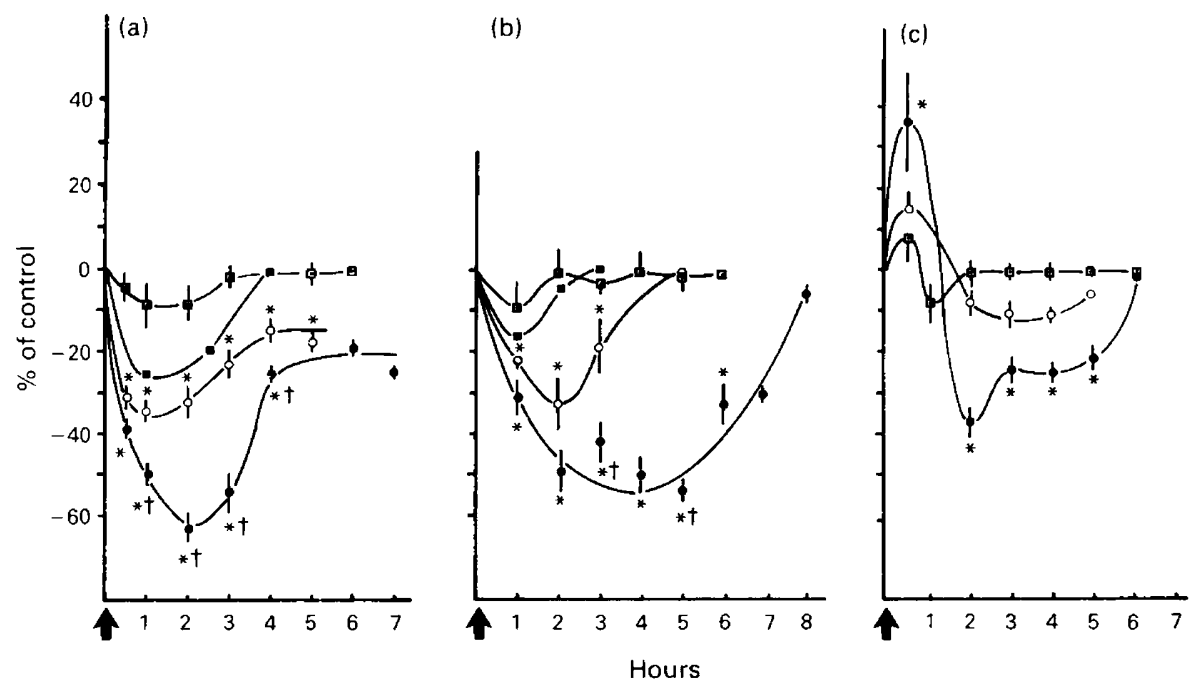

Fig. 5. Dose-response curves of EMG activity after graded doses of prazosin (, $0.75 \mathrm{mg} / \mathrm{kg}$; $0,1.5 \mathrm{mg} / \mathrm{kg} ; 0,3 \mathrm{mg} / \mathrm{kg}$ ) or saline (๑). (a) Amplitude of spike potentials; (b) frequency of the bursts; (c) duration of the bursts. Arrow indicates the time when prazosin was injected; EMG recordings were made between 13:00 and 22:00 $\mathrm{h}$ on Day 4. The changes are expressed as a percentage of the value for untreated rats. For each dose-response curve $\mathrm{N}=4-6$; ${ }^{*} P<0.025$ vs saline; $\dagger P<0.025$ vs $1.5 \mathrm{mg}$ prazosin $/ \mathrm{kg}$.
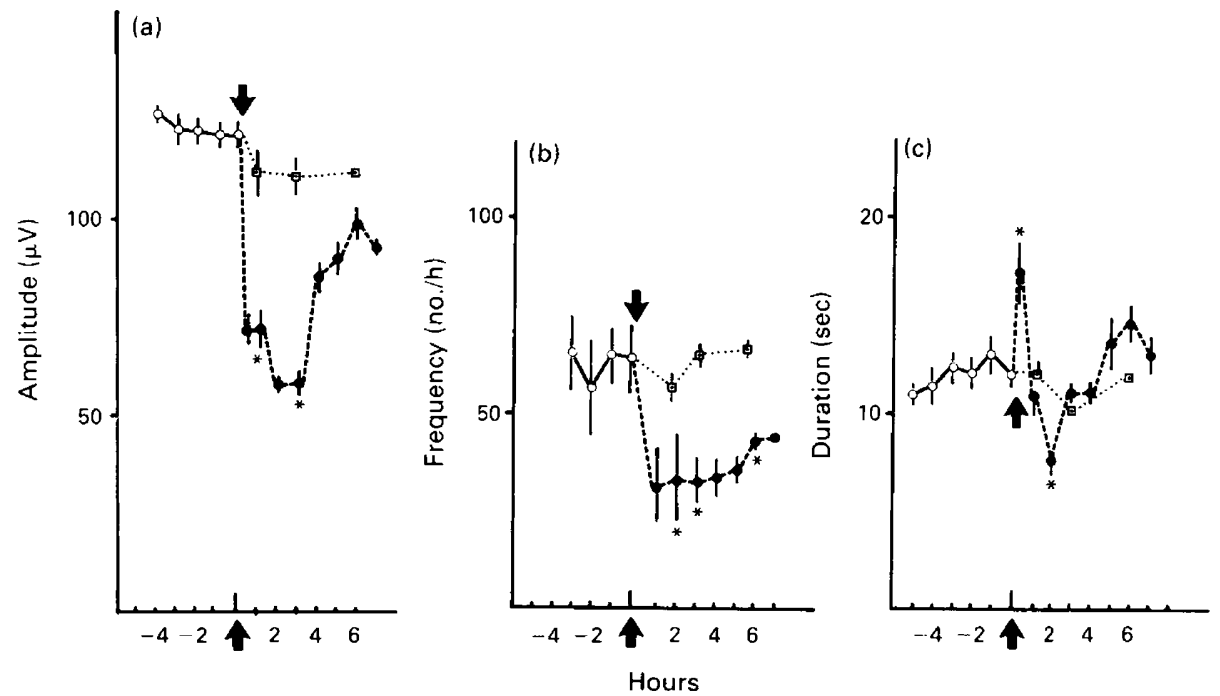

Fig. 6. EMG activity of the uterus before $(O)$ and after $(\bullet)$ injection of $1 \mathrm{mg}$ prazosin or saline (घ). (a) Amplitude of spike potentials; (b) frequency of the bursts; (c) duration of the bursts: EMG activity was recorded between $13: 00$ and 22:00 h on Day $4 .{ }^{*} P<0.05$ vs saline; $\mathrm{N}=4$.

Psychoyos (1966), Forcelledo et al. (1981) and Villalon et al. (1982). In isolated strips of myometrium from the gilt, another polytocous species, Pope et al. (1982a) have demonstrated that myometrial contractility increased when embryos were migrating and they suggest an involvement of oestradiol in the intrauterine migration of embryos (Pope et al., 1982b). 

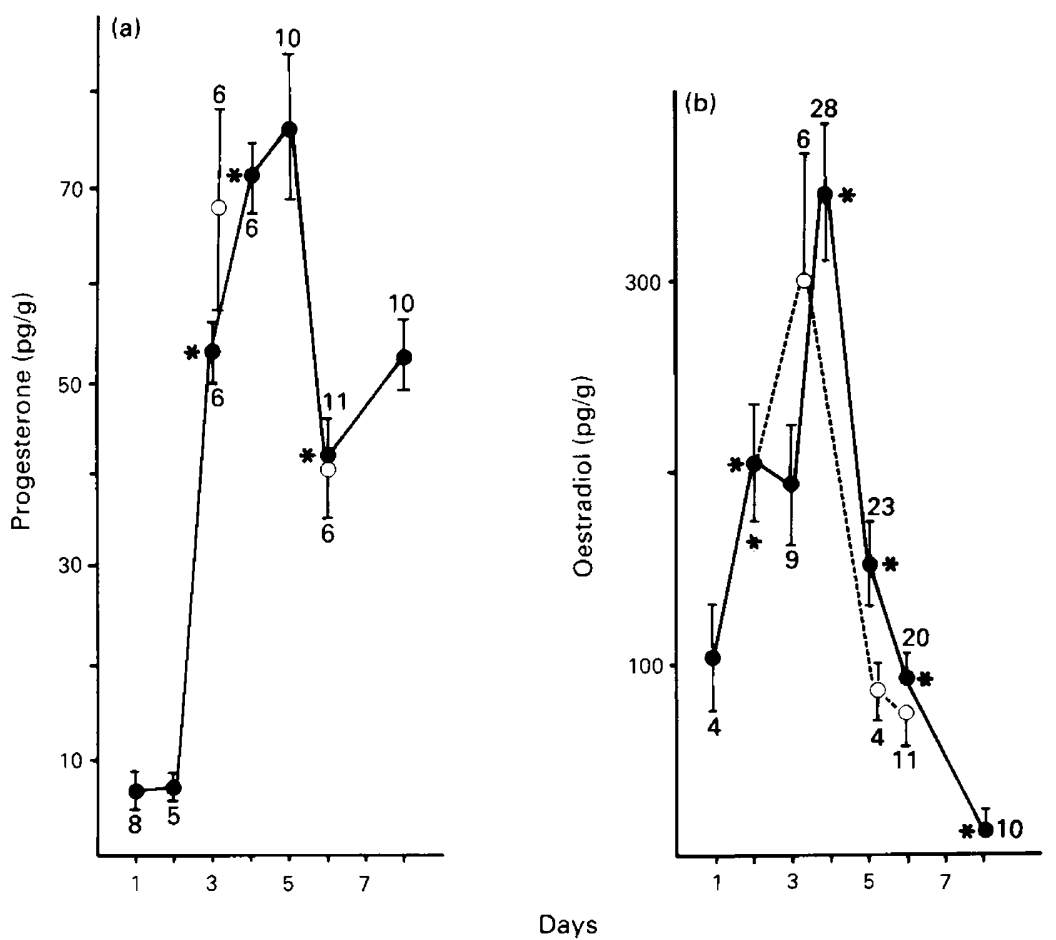

Fig. 7. Uterine concentrations of progesterone (a) and oestradiol (b) during the first week of pregnancy in intact pregnant rats $(\mathbf{O})$ or after insertion of electrodes into the myometrium $(O)$. Each value represents mean \pm s.e.m. for the number of uterine horns assessed. ${ }^{*} P<0.05 v \mathrm{~s}$ previous stage of pregnancy.

After the surgical procedure for EMG activity recordings, uterine horns bearing electrodes showed no major structural or hormonal impairment, as demonstrated by histological study of tissues and steroid assays. Therefore, the presence of electrodes in the myometrium may be responsible for the reduction ( $-44 \%$ ) of blastocyst sites (identified after injection of Evans' blue) since in the contralateral unoperated horn their number remained similar to that of normal control rats at the same stage of pregnancy $(6.6 \pm 0.8 v s 6.1 \pm 0.5$ : see Legrand $e t$ al., 1987). It is therefore likely that the appearance of greater myometrial activity which coincided with intrauterine blastocyst migration can be implicated in the control of blastocyst transfer and/or spacing. The first evidence for this theory came from the work of Pusey et al. (1980) which demonstrates that intrauterine distribution of blastocysts can be disrupted after i.v. infusion of pig relaxin, a potent myometrial inhibitory polypeptide. As shown above, the myometrium on Day 4 of pregnancy exhibited longer bursts of spike potentials, the amplitude increasing about 2-fold, with a strong rhythmic activity well developed at the utero-tubal junction. Therefore, bursts generated there failed to spread over large areas of myometrium (pairs of electrodes were placed 2-3 cm apart) and probably could not initiate a co-ordinated response along the uterine horn. This observation is in good agreement with previous data of Talo \& Kärki (1977). These changes of EMG activity occur just after the uterine rise of oestradiol, which correlates with an increase of oestrogen secretion from the maternal ovaries (Yoshinaga et al., 1969), and coincide with the highest level of uterine progesterone. Since uterine smooth muscle activity has been shown to be profoundly influenced by steroids, it is probable that the early pregnant myometrium exhibits changes in electrical activity in response to the steroidal environment. Indeed, in ovariectomized rats given hormone replacement therapy, administration of progesterone in addition to oestradiol resulted in strong rhythmic 
activity (Fuchs, 1976). Moreover, under the influence of increasing levels of uterine progesterone, bursts become progressively unpropagated: progesterone acts as an antioestrogen with regard to gap junction formation and consequently inhibits the development of a well co-ordinated activity in the myometrium (Garfield et al., 1980; Garfield, 1985; McKenzie \& Garfield, 1985). In addition, in-vitro experiments on progesterone-dominated rat and rabbit myometrium have demonstrated multiple pacemaker sites within the uterus and poor propagation of electrical activity (Marshall, 1962; Ichikawa \& Bortoff, 1970). Our observations in the afternoon of Day 4 demonstrate that myometrial cells were potentially capable of generating repetitive burst discharges; therefore progesterone domination resulted in a low conduction of electrical activity preventing the development of propulsive contraction waves. Such activity might be of major physiological importance for moving each blastocyst to its implantation site and/or for first general spacing; the fate of the unattached blastocysts, particularly in the caudal portion of the uterine horns, would depend on both unpropagated activity and mechanical activity of the cervix. At this stage of pregnancy, there is evidence that other regulatory factors, such as prostaglandin (Pope et al., 1982) and noradrenaline (Legrand et al., 1987) are also implicated. Our results clearly showed that blockade of myometrial $\alpha_{1}$-adrenoceptors by prazosin depressed in a dose-dependent manner the amplitudes of the spikes as well as the frequency of the bursts, illustrating that myometrial activity at the time of blastocyst distribution is really under the control of noradrenaline. We have no rational explanation for the biphasic response observed for burst duration after prazosin administration. In addition, Pope et al. (1982) reported that exposure of the myometrium to propranolol (a $\beta$ adrenergic antagonist) and noradrenaline, increased the frequency of contraction of isolated muscle strips from pregnant gilts from Day 9 to Day 12 . The possibility that myometrial contractile activity is causally related to embryo migration or spacing has been suggested by previous data of Pusey et al. (1980) and Legrand et al. (1987).

We thank Mrs C. Rigolot for helpful technical assistance; Mrs A. Demond for typing this manuscript; and Mr M. Gouzy for illustrations. This work was supported by a grant from the Fondation de Recherche en Hormonologie (Dr R. Scholler), contract 7586008 , and CONACYT, Mexico.

\section{References}

Böving, B.G. (1971) Biomechanics of implantation. In The Biology of the Blastocyst, pp. 423442 . Ed. R. J. Blandau. University of Chicago Press.

De Marinis, R.M., Wise, M., Thieble, J.P. \& Ruffolo, R.R. (1987) Structure-activity relationships for $\alpha_{1}-$ adrenergic receptor agonists and antagonists. In Alpha-1 Adrenergic Receptors, pp. 211-265. Ed. R. R. Ruffolo. Humana Press Inc., Clifton.

Forcelledo, M.L., Vera, R. \& Croxatto, H.B. (1981) Ovum transport in pregnant, pseudo-pregnant and cyclic rats and its relationship to oestradiol and progesterone blood levels. Biol. Reprod. 24, 760-765.

Fuchs, A.R. (1976) Influence of estrogen and progesterone on uterine motility reassessed. Gynecol. Invest. 7, 99-105.

Garcia-Villar, R., Toutain, P.L. \& Ruckebusch, Y. (1984) Pattern of electrical activity of the uterus and cervix from mating to parturition. J. Reprod. Fert. 72, 143152.

Garfield, R.E. (1985) Cell-to-cell communication in smooth muscle. In Calcium and Contractility, pp. 143-173. Eds A. K. Grover \& E. E. Daniel. The Humana Press, Clifton.
Garfield, R.E., Kannan, M.S. \& Daniel, E.E. (1980) Gap junction formation in myometrium: control by estrogens, progesterone and prostaglandins. Am. $J$. Physiol. 238, C81-C89.

Hobbs, D.C. \& Towmey, T.M. (1979) Protein binding properties of prazosin. Res. Commun. Chem. Pathol. Pharmacol. 25, 189-192.

Ichikawa, S. \& Bortoff, A. (1970) Tissue resistance of the progesterone dominated rabbit myometrium. Am. J. Physiol. 197, 935-942.

Ishikawa, M. \& Fuchs, A.R. (1978) Electrical and mechanical activity of rat uterus in vivo during the estrous cycle. Am. J. Obstet. Gynecol. 132, 6I1-619.

Krishnamurti, C.R., Kitts, D.D., Kitts, W.D. \& Tompkins, J.G. (1982) Myoelectrical changes in the uterus of the sheep around parturition. J. Reprod. Fert. 64, 59-67.

Legrand, C. \& Maltier, J.P. (1981) Activité électrique de l'utérus chez la rate préparturiente. In Utérus et Fécondité, pp. 61-68. Eds C. Boury-Heyler, P. Mauléon \& Y. Rochet. Masson, Paris.

Legrand, C. \& Maltier, J.P. (1986) Evidence for a noradrenergic transmission in the control of parturition in the rat. J. Reprod. Fert. 76, 415-424. 
Legrand, C., Banuelos-Nevarez, A., Rigolot, C. \& Maltier, J.P. (1987) Comparative effects of 6-hydroxydopamine and $\alpha$-adrenoceptor antagonists on intrauterine migration and spacing of blastocysts in the rat. J. Reprod. Fert. 81, 51-58.

Marshall, J.M. (1962) Regulation of activity in uterine smooth muscle. Physiol. Rev. 42, 213-227.

McKenzie, L.W. \& Garfield, R.E. (1985) Hormonal control of gap junctions in the myometrium. $A m . J$. Physiol. 248, C296-C308.

Naaktgeboren, C., Van der Weyden, G.C. Klopper, P.J., Kroon, C.H., Schoof, A.G. \& Taverne, M.A.M. (1973) Electrophysiological observations of uterine motility during the oestrous cycle in sheep. J. Reprod. Fert. 35, $511-518$.

Pope, W.F., Maurer, R.R. \& Stormshak, F. (1982a) Intrauterine migration of the porcine embryo-interaction of embryo, uterine flushings and indomethacin on myometrial function in vitro. J. Anim. Sci. 55, 1169-1178.

Pope, W.F., Maurer, R.R. \& Stormshak, F. (1982b) Intrauterine migration of the porcine embryo: influence of estradiol-17 $\beta$ and histamine. Biol. Reprod. 27, 575-579.

Prud'homme, M.J. (1976) Etude électromyographique de l'organisation de la motricité utérine au cours de l'oestrus chez la Brebis. Annls Biol. anim. Biochim. Biophys. 16, $821-831$

Prud'homme, M.J. \& Bosc, M.J. (1977) Motricité utérine de la brebis avant, pendant et après la parturition spontanée ou après traitement par la dexaméthasone. Annls Biol anim. Biochim. Biophys. 17, 9-19.

Psychoyos, A. (1961) Perméabilité capillaire et décidualisation utérine. C, r. hebd. Séanc. Acad. Sci., Paris 252, 1515-1518.

Psychoyos, A. (1966) Etude des relations de l'oeuf et de l'endomêtre au cours du retard de la nidation ou des premières phases du processus de nidation chez la ratte. C.r.hebd. Séanc. Acad. Sci., Paris 263, 1755-1758.
Psychoyos, A. (1971) Methods for studying changes in capillary permeability of the endometrium. In Methods in Mammalian Embryology, pp. 334-338. Ed. J. C. Daniel, Jr. W.H. Freeman, New York.

Pusey, J., Kelly, W.A., Bradshaw, J.M.C. \& Porter, D.G. (1980) Myometrial activity and the distribution of blastocysts in the uterus of the rat: interference by relaxin. Biol. Reprod. 23, 394-397.

Rogers, P.A.W., Murphy, C.R., Squires, K.R. \& Mac Lennan, A.H. (1983) Effects of relaxin on the intrauterine distribution and antimesometrial positioning and orientation of rat blastocysts before implantation. J. Reprod. Fert. 68, 431-435.

Ruckebusch, Y. \& Bayard, F. (1975) Motility of the oviduct and uterus of the cow during the oestrous cycle. J. Reprod. Fert. 43, 23-32.

Ruffolo, R.R., Jr (1984) Interactions of agonists with peripheral $\alpha$-adrenergic receptors. Fedn Proc. Fedn Am. Socs exp. Biol. 43, 2910-2916.

Talo, A. \& Kärki, A.E. (1977) Electrical activity of the rat uterus during early pregnancy and abortion. Acta physiol. scand. 100, 377-381.

Taverne, M.A.M., Naaktgeboren, C. \& van der Weyden, G.C. (1979) Myometrial activity and expulsion of fetuses. Anim. Reprod. Sci. 2, 117-131.

Villalon, M., Ortiz, M.E., Aguayo, C., Munoz, J. \& Croxatto, H.B. (1982) Differential transport of fertilized and unfertilized ova in the rat. Biol. Reprod. 26, 337-341.

Wolfs, G.M.J. \& van Leeuwen, M. (1979) Electromyographic observations on the human uterus during labour. Acta obstet. gynec. Scand., Suppl. 90, $1-61$.

Yoshinaga, K., Hawkins, R.A. \& Stocker, J.F. (1969) Estrogen secretion by the rat ovary in vivo during the estrous cycle and pregnancy. Endocrinology 85, $103-112$.

Received 13 June 1988 